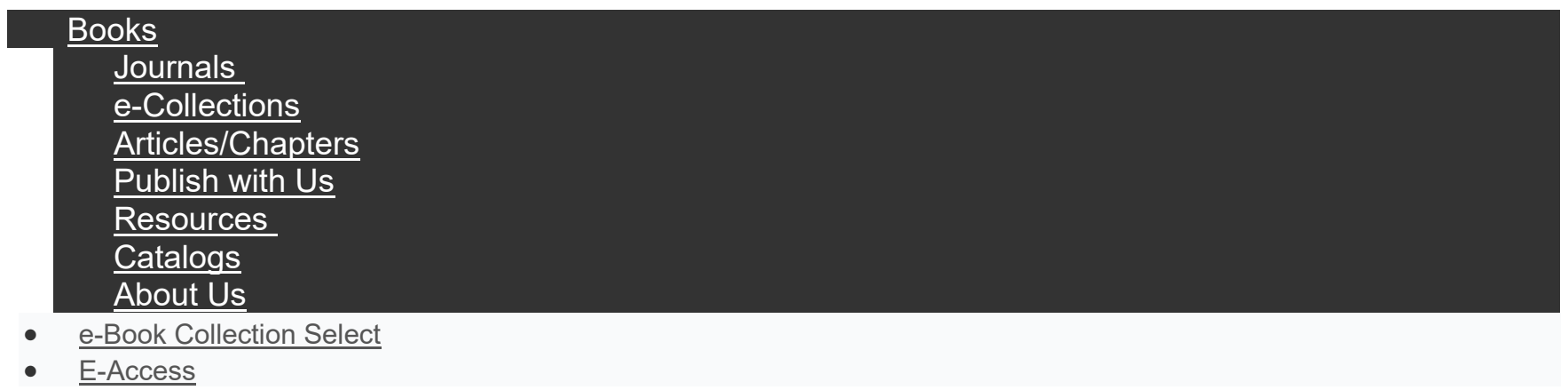

\title{
Management of Institutional Repositories (IR) in Developing Countries
}

Jerome Idiegbeyan-Ose (Covenant University, Nigeria), Goodluck Ifijeh (Covenant University, Nigeria), Juliana IwuJames (Covenant University, Nigeria) and Julie Ilogho (Covenant University, Nigeria)

Source Title: Digital Libraries and Institutional Repositories: Breakthroughs in Research and Practice Copyright: (C) 2020 Pages: 27

DOI: 10.4018/978-1-7998-2463-3.ch022

OnDemand PDF Download:

Available

\section{$\$ 37.50$}

\section{Current Special Offers}

\section{Abstract}

The chapter discusses the management of institutional repositories (IR) in developing countries. It starts with the introduction of the concept of institutional repositories and its origin. Various definitions of institutional repositories are highlighted. The chapter goes further to discuss the features of institutional repositories such as infrastructure, hosted service, customer support, content organization and control, content discovery, publication tools, reporting, multimedia, social features and notifications, and so on. It further analyses vital issues in management of institutional repositories. Peculiar issues in open access for developing countries are also identified and discussed. The chapter covers the roles of libraries and librarians in the management of institutional repositories; the roles include collection development and management, software acquisition and training, formulation of guidelines for standard metadata and catalogue system, assessment of submission for standard and quality, persuading authors to contribute their intellectual works, enlightenment on copyright issues, information literacy in the use of institutional repositories, promotion and marketing of institutional repositories. The chapter further highlights the challenges and intervention strategies in the management of institutional repositories in developing countries; it enumerates the challenges to include: personnel and technical staff, ICT equipment and infrastructure, lack of awareness and advocacy, inadequate funding, poor policy guidelines, poor power supply, open access, software, copyright law and inadequate internet bandwidth. Based on these, the chapter recommends that an aggressive enlightenment programme should be carried out from time to time; developing countries and their higher institutions should wake up to their responsibilities by formulating policies on institutional repositories (IR); developing countries should also come together to form consortia in the areas of software selection and deployment for institutional repositories. Management of institutions in these countries should make funds available for the smooth running of their institutional repositories, and so on. The chapter concludes with the need for academic institutions and their libraries to pay more attention to the funding and development of institutional repositories in order to provide more effective and efficient access to digital information services to the global academic community.

$$
\text { Chapter Preview }
$$




\section{Introduction}

$\mathrm{m}$ those resources that have often been out of reach to libraries in developing countries. 